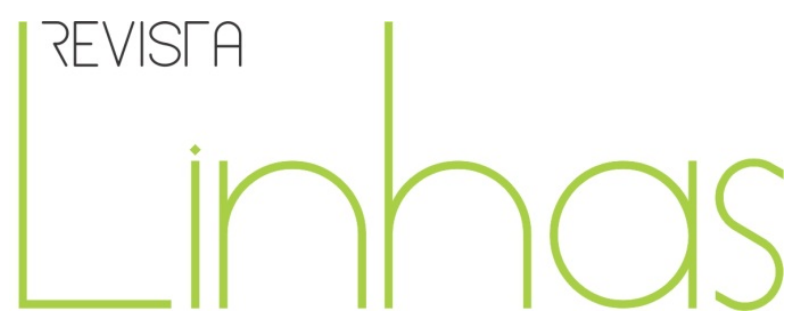

\title{
Ser professor na escola: de aluno a professor no estágio curricular supervisionado na licenciatura em Educação
}

\section{Física}

\begin{abstract}
Resumo
Este estudo objetivou analisar como acontece a passagem de aluno a professor durante a realização dos Estágios Curriculares Supervisionados (ECS) I-II-III na percepção dos acadêmicos da Licenciatura em Educação Física do Centro de Educação Física e Desportos (CEFD) da Universidade Federal de Santa Maria (UFSM). A metodologia empregada caracterizou-se pelo enfoque fenomenológico sob a forma de estudo de caso com abordagem qualitativa. $O$ instrumento utilizado para a coleta de informações foi uma entrevista semiestruturada. A interpretação das informações foi a análise de conteúdo. Os participantes foram vinte (20) acadêmicos do $7^{\circ}$ semestre do curso de Licenciatura em Educação Física do CEFD/UFSM. Concluímos que foi possível identificar seis momentos de passagem de aluno a professor e também oito transformações ocasionadas pelos momentos de passagem de aluno a professor na percepção dos acadêmicos estudados.
\end{abstract}

Palavras-chave: Educação Física; Formação de professores; Formação inicial; Estágio curricular supervisionado; Ser professor.

\section{Hugo Norberto Krug}

Doutor em Educação pela Universidade Federal de Santa Maria - UFSM - Brasil hnkrug@bol.com.br

\section{Rodrigo de Rosso Krug}

Doutorando em Ciências Médicas pela Universidade Federal de Santa Catarina - UFSC - Brasil rodkrug@bol.com.br

Marta Nascimento Marques

Mestre em Educação pela Universidade Federal de Santa Maria - UFSM - Brasil martinhanm@yahoo.com.br

\section{Victor Julierme Santos da} Conceição

Doutorando em Ciências do

Movimento Humano pela

Universidade federal do Rio

Grande do Sul - UFRS - Brasil victorjulierme@yahoo.com.br

\section{Para citar este artigo:}

KRUG, Hugo Norberto; KRUG, Rodrigo de Rosso; MARQUES, Marta Nascimento; CONCEIÇÃO, Victor Julierme Santos da. Ser professor na escola: de aluno a professor no estágio curricular supervisionado na licenciatura em Educação Física. Revista Linhas. Florianópolis, v. 16, n. 30, p. 248 - 269, jan./abr. 2015.

DOI: $10.5965 / 1984723816302015248$

http://dx.doi.org/10.5965/1984723816302015248 


\title{
Be a teacher at school: from student to teacher on stage in supervised curriculum degree in Physical Education
}

\begin{abstract}
This study aimed to analyze with happens the passage of student the teacher during the course of Curricular Supervised (ECS) I-II-III in the perception of the academic degree in Physical Education of Center Physical Education and Sports (CEFD) of Federal University of Santa Maria (UFSM). The methodology maid characterized by the phenomenological approach in the form of case study with qualitative approach. The instrument used for data collection was a semi-structured interview. The interpretation of information was content analysis. Participants were twenty (20) students from the 7th semester of the Bachelor's Degree in Physical Education CEFD/UFSM. We concluded that it was possible to identify six moments of passage of student from teacher and also eight transformations caused by the moments of passage of student from teacher perceptions of academic study.
\end{abstract}

Keywords: Physical Education; Teacher training; Initial training; Stage in supervised curriculum; Being teacher. 


\section{Introduzindo a investigação}

Segundo Silva (2010), os cursos de formação de professores de Educação Física têm a função de proporcionar aos acadêmicos disciplinas, conhecimentos, estágios e experiências que possibilitem uma base teórico-prática para atuarem nas escolas. Destaca que é na formação inicial que o acadêmico passa a se ver como professor, buscando perceber-se e construir-se como professor, revendo as imagens e representações da profissão docente, reconstruindo-as.

Diante de tais afirmativas, decorre atribuirmos importância ao estágio no processo de formação do professor, pois, de acordo com Krüger; Conceição e Krug (2007) o Estágio Curricular Supervisionado (ECS) é uma fase do processo de aprender a ser professor. Segundo Isaia (2006), a aprendizagem docente é um processo que envolve a apropriação de conhecimentos, saberes e fazeres próprios ao magistério, que estão vinculados à realidade concreta da atividade docente em seus diversos campos de atuação e em seus respectivos domínios.

Já Krug e Krug (2012) consideram que, na formação inicial de professores, é durante o ECS que os acadêmicos exercitam a transição da condição de estudantes para a condição de professor. Nesse sentido, Bernardi et al. (2008, p. 19) observam que o estágio “é uma simulação da atuação do professor". Também Leone e Leite (2001) destacam que o processo de transição do 'ser estudante' para o 'ser professor' começa durante a formação inicial, por meio da realização de atividades de estágio e prática de ensino, de conhecer, refletir e interpretar a cultura escolar.

Reforçando esta linha de pensamento, Bernardi et al. (2008) colocam que a disciplina de ECS na formação inicial de professores tem a função de colocar os acadêmicos frente à frente com a sua futura profissão. Os autores destacam que o acadêmico precisa deixar de lado a postura de aluno, a qual assume desde a sua educação básica, para assumir a postura de docente. No entanto, essa passagem não é automática, ela necessita de tempo e experiência para acontecer.

Neste contexto de problematização e objetivação, focamos o nosso interesse investigativo na Universidade Federal de Santa Maria (UFSM) e, particularmente, no ECS 
do curso de Licenciatura em Educação Física do Centro de Educação Física e Desportos (CEFD). Nesse espaço formativo, foi realizada uma reforma curricular, em 2005, fundamentada nas Resoluções n. 01 (BRASIL, 2002a) e n. 02 (BRASIL, 2002b) do Conselho Nacional de Educação/Conselho Pleno (CNE/CP) de 2002.

Desta forma, convém salientar que, em consonância com a Resolução n. 02 do CNE/CP (BRASIL, 2002b), a atual grade curricular do curso de Licenciatura em Educação Física do CEFD/UFSM (CEFD, 2005) proporciona os Estágios Curriculares Supervisionados I, II e III nos $5^{\circ}, 6^{\circ}$ e $7^{\circ}$ semestres do mesmo, realizados respectivamente no Ensino Médio, nas Séries/Anos Finais do Ensino Fundamental e nas Séries/Anos Iniciais do Ensino Fundamental, com carga de 120 horas destinadas a cada estágio, somando-se a essas 360 horas, mais 45 horas de Seminário em Estágio Curricular Supervisionado, no $8^{\circ}$ semestre do curso, totalizando, então, 405 horas. Cabe ainda destacar que os ECS I, II e III possuem em suas ementas objetivos que envolvem o desenvolvimento de diversas atividades no contexto escolar, tais como: inserção, observação e docência.

Assim, considerando este 'aprender a ser professor' no estágio, esta 'passagem de aluno a professor', foi que surgiu a questão problemática que norteia esta investigação: Como os acadêmicos de graduação, em situação de Estágio Curricular Supervisionado, percebem o processo de transição da condição de aluno para professor, em uma perspectiva de constituição da identidade docente, ou seja, do tornar-se professor?

A partir desta questão problemática, estruturamos o seguinte objetivo geral: analisar como acontece a passagem de aluno a professor durante a realização dos ECS I-IIIII na percepção dos acadêmicos da Licenciatura em Educação Física do CEFD/UFSM.

Para alcançarmos este objetivo, traçamos os seguintes objetivos específicos: 1) Identificar os momentos de passagem de aluno a professor na percepção dos acadêmicos da Licenciatura em Educação Física do CEFD/UFSM durante a realização dos ECS I-II-III; e, 2) Identificar as transformações ocasionadas pelos momentos de passagem de aluno a professor na percepção dos acadêmicos da Licenciatura em Educação Física do CEFD/UFSM durante a realização dos ECS I-II-III.

Para justificar a realização desta investigação citamos llha et al. (2009), que consideram que o ECS é um espaço em que o acadêmico se constitui enquanto 
profissional da educação. Embora essa constituição perpasse toda a sua trajetória escolar/acadêmica e o seu desenvolvimento profissional, é através do estágio que ocorre uma maior aproximação com a realidade escolar e o início da profissão, bem como, a consolidação e criação de um modelo próprio de ação docente construído através das relações entre a experiência e o conhecimento, isto é, a práxis educativa. Também mencionamos Ilha; Krug e Krug (2009) ao observarem que estudos dessa natureza podem oferecer subsídios para modificações no contexto da formação de professores, particularmente na compreensão do ECS, auxiliando, consequentemente, na melhoria da qualidade da formação inicial.

\section{Os procedimentos metodológicos da investigação}

A metodologia empregada nesta investigação caracterizou-se pelo enfoque fenomenológico sob a forma de estudo de caso com abordagem qualitativa. Conforme Triviños (1987, p.125), a pesquisa qualitativa de natureza fenomenológica "surge como forte reação contrária ao enfoque positivista nas ciências sociais", privilegiando a consciência do sujeito e entendendo a realidade social como uma construção humana. $O$ autor explica que na concepção fenomenológica da pesquisa qualitativa, a preocupação fundamental é com a caracterização do fenômeno, com as formas que se apresenta e com as variações, já que o seu principal objetivo é a descrição.

Para Fazenda (1989, p.58) "a descrição não se fundamenta em idealizações, imaginações, desejos e nem num trabalho que se realiza na subestrutura dos objetos descritos; é, sim, um trabalho descritivo de situações, pessoas ou acontecimentos em que todos os aspectos da realidade são considerados importantes".

Já, segundo Lüdke e André (1986, p. 18), o estudo de caso enfatiza "a interpretação em contexto". Godoy (1995, p.35) coloca que:

[...] o estudo de caso tem se tornado na estratégia preferida quando os pesquisadores procuram responder às questões "como" e "por que" certos fenômenos ocorrem, quando há pouca possibilidade de controle sobre os eventos estudados e quando o foco de interesse é sobre 
fenômenos atuais, que só poderão ser analisados dentro de um contexto de vida real.

De acordo com Goode e Hatt (1968, p. 17) “o caso se destaca por se constituir numa unidade dentro de um sistema mais amplo". O interesse incide naquilo que ele tem de único, de particular, mesmo que posteriormente fiquem evidentes estas semelhanças com outros casos ou situações.

Para a coleta de informações foi utilizada uma entrevista semiestruturada. Para Triviños (1987), a entrevista é uma das principais fontes de informações da pesquisa qualitativa, pois, através dela, ao mesmo tempo em que o investigador é valorizado, o informante alcança a liberdade e a oportunidade necessária para enriquecer a investigação. Parte de certos questionamentos básicos, apoiados em teorias e hipóteses, oferecendo amplo campo de interrogativas, fruto de novas hipóteses que vão surgindo à medida que se recebem as respostas.

Para a construção das questões norteadoras que compuseram a entrevista, buscamos uma relação direta com objetivos específicos destacando dois pontos principais: os momentos de passagem e as transformações ocasionadas por esses momentos de passagem. Dessa forma, as questões que balizaram as entrevistas foram as seguintes: 1) Quais foram os momentos de passagem de aluno a professor percebidos por você durante a realização dos ECS I-II-III? 2) Quais foram as transformações ocasionadas pelos momentos de passagem de aluno a professor percebidos por você durante a realização dos ECS I-II-III?

As interpretações das entrevistas ocorreram pela análise de conteúdo que, segundo Bardin (1977), é o conjunto de técnicas de análise das comunicações visando obter, por procedimentos sistemáticos e objetivos de descrição do conteúdo das mensagens, indicadores (quantitativos ou não) que permitam a inferência de conhecimentos relativos às condições de produção/recepção (variáveis inferidas) dessas mensagens. Ainda esse autor coloca que a utilização da análise de conteúdo possui três etapas principais: $1^{a}$ ) A pré-análise - que trata do esquema de trabalho, envolve os primeiros contatos com os documentos de análise, a formulação de objetivos, a definição dos procedimentos a serem seguidos e a preparação formal do material; $2^{\mathrm{a}}$ ) A exploração 
do material - que corresponde ao cumprimento das decisões anteriormente tomadas, isto é, leitura de documentos, categorização, entre outros; e, $3^{a}$ ) O tratamento dos resultados - fase em que os dados são lapidados, tornando-os significativos, sendo que esta etapa de interpretação deve ir além dos conteúdos manifestos nos documentos, buscando descobrir o que está por trás do imediatamente apreendido.

Participaram da investigação vinte (20) acadêmicos do $7^{\circ}$ semestre do curso de Licenciatura em Educação Física (Currículo 2005) do CEFD/UFSM, matriculados na disciplina de Estágio Curricular Supervisionado III (Séries/Anos Iniciais do Ensino Fundamental), no $1^{\circ}$ semestre letivo de 2012. Optamos pelo ECS III por esse ser o último estágio dos acadêmicos e, portanto, significando a última experiência com a escola na grade curricular do curso de Licenciatura em Educação Física do CEFD/UFSM. É necessário esclarecer que todos os acadêmicos desse semestre foram convidados a participar e todos aceitaram e tiveram disponibilidade de tempo para integrar a investigação. Esse processo que Molina Neto (2004) denomina de participação espontânea corresponde à participação voluntária do colaborador da pesquisa e destaca que esse tipo de participação influencia positivamente no volume e credibilidade das informações disponibilizadas pelos colaboradores. As entrevistas foram gravadas após a permissão e assinatura do Termo de Consentimento e Livre Esclarecimento, sendo transcritas e lidas pelos entrevistados de acordo com esse mesmo termo citado.

\section{Os resultados e as discussões da investigação}

Os resultados e as discussões desta investigação foram explicitados e orientados pelos objetivos específicos. Esses objetivos nortearam a apresentação das informações, que são tratadas neste momento. Para materializar os fenômenos que apareceram nas entrevistas, destacamos os depoimentos dos participantes e os analisamos à luz dos referenciais escolhidos para dar conta das essências do 'processo de tornar-se professor'. 


\section{Os momentos de passagem de aluno a professor na percepção dos acadêmicos estudados}

Os depoimentos mostraram que todos os acadêmicos perceberam momentos de passagem de aluno a professor durante a realização dos ECS I-II-III do curso de Licenciatura em Educação Física do CEFD/UFSM. Esses momentos se referem ao processo de inserção na cultura escolar, momento de primeiros contatos na posição de mediador de um determinado conhecimento junto a um grupo de estudantes.

O fenômeno da inserção na escola foi mencionado como o primeiro momento de passagem de aluno a professor. Pimenta e Lima (2004, p. 43) salientam que cabe ao estágio possibilitar que os acadêmicos "compreendam a complexidade das práticas institucionais e das ações praticadas por seus profissionais como alternativa no preparo para a sua inserção profissional”. De acordo com Marcelo García (1999), esse tipo de inserção e conhecimento não se adquire senão em contato com os alunos e as escolas reais, e assim, as práticas de ensino constituem-se na oportunidade mais adequada para promover essa articulação.

A regência da disciplina de Educação Física foi outro fenômeno percebido como momento de passagem de aluno a professor. Na compreensão de Santos Júnior e Krug (2008) o acadêmico se constitui como profissional no momento em que passa a atuar no contexto de sua profissão, na medida em que se torna ativo na elaboração, execução e avaliação de seu próprio trabalho docente. Diante disso é que os estágios e projetos configuram-se num veículo essencial para a construção de concepções de educação e de professor ainda no currículo de formação inicial. Nesse sentido, para desempenhar o papel de um bom educador e ministrar aulas de qualidade, existe a necessidade do profissional não querer apenas dominar o conhecimento teórico, mas fazer a relação com o conhecimento da prática, da experiência. Através do conhecimento científico, teremos a capacidade de agregar subsídios e dar embasamento para manter ou modificar nossa prática (MARQUES; ILHA; KRUG, 2009).

O fenômeno da relação com os estudantes na escola foi percebido como mais um momento de passagem de aluno a professor. Cunha (1996) compreende a aula como um lugar de interação entre pessoas e, portanto, um momento único de troca de influências. 
A relação professor-aluno, no sistema formal, é parte da educação e insubstituível na sua natureza. Destaca que o aluno espera ser reconhecido como pessoa e valoriza no professor as qualidades que os ligam afetivamente. Enfim, durante o desenrolar das aulas, o estagiário pode estabelecer uma relação positiva com os alunos, que ultrapasse a barreira dos métodos tradicionais na relação verticalizada de professor-aluno e passe para uma relação de amizade, relação esta que é de extrema importância para facilitar o processo de ensino-aprendizagem. Além disso, o professor inserido no processo educacional é um elemento importantíssimo nas relações educativas e em tudo que acontece no ambiente escolar, podendo assim transformar a realidade escolar e proporcionar meios para promover a aprendizagem dos alunos, distanciando-se dessa forma, do modelo tradicional que assombra as instituições de ensino. O debate promovido sobre esse contato direto com os estudantes e a rotina escolar, norteia a compreensão sobre o ser professor responsável pela mediação da construção de conhecimento com um grupo de estudantes.

Ser chamado de professor pelos estudantes também foi mais um fenômeno percebido como momento de passagem de aluno a professor. De acordo com a colocação feita pelos acadêmicos, certamente o estágio pedagógico é uma das experiências mais enriquecedoras que o acadêmico poderá ter, pois essa poderá ser a primeira e única atuação docente durante sua formação inicial, ou seja, um momento único em que é chamado e tratado como 'professor'. Segundo Marques; Ilha e Krug (2009), através dessa vivência o acadêmico (re)constrói conhecimentos, dentre eles, questões de planejamento, ou seja, de funcionamento da aula, organização dos conteúdos e atividades no espaço e no tempo, metodologias e estratégias a serem utilizadas, bem como a relação professor-aluno. Dessa forma, o trabalho realizado no âmbito do ECS, é de extrema importância e muito significativo para a formação do acadêmico de Educação Física, na medida em que proporciona um ambiente de ensino favorável à construção da identidade docente desse futuro professor. Veiga (2005) contribui a esse respeito ao esclarecer que o espaço escolar é um lugar de realização e avaliação de seu projeto educativo, uma vez que preconiza organizar o trabalho pedagógico com base em seus alunos. 
Outro fenômeno percebido como momento de passagem de aluno a professor foi relativo às tomadas de decisões frente aos acontecimentos das aulas. Tardif, Lessard e Lahaye (1991), ao abordarem o rito de passagem de aluno a professor, consideram que no exercício cotidiano de sua função, o professor defronta-se com vários limites concretos que não são previsíveis e passíveis de uma definição acabada. O docente desenvolve, então, habilidades pessoais, tais como capacidade de improvisação, macetes, gestos, atitudes e estilos que possibilitam vencer as barreiras e construir uma maneira própria de ensinar. Assim, as tomadas de decisões frente a esse contato direto com os estudantes e a rotina escolar norteiam a compreensão sobre o ser professor responsável pela mediação da construção de conhecimento com um grupo de estudantes.

O fenômeno da constatação de mudanças relativas aos conhecimentos dos estudantes foi mencionado como o último momento de passagem de aluno a professor. A esse respeito, salientamos que o professor é o principal agente que proporciona mudanças relativas no conhecimento de seus alunos. Segundo Chicati (2000), a aprendizagem é uma modificação relativamente duradoura do comportamento, através do treino, experiência e observação. No entanto, para que ocorra essa aprendizagem, se faz necessário que o indivíduo esteja motivado pois a experiência e a observação, entre outros fatores, somente estarão presentes no cotidiano do aluno se esse possuir motivos que o levem a executar as tarefas. Acerca disso, cabe ao professor a responsabilidade de desenvolver um trabalho adequado à realidade e interesse de seus alunos possibilitando, assim, mudanças na aprendizagem. De acordo com Marques (1989, p. 24) “[...] não basta levar à sala de aula conteúdos criticamente selecionados e estrategicamente organizados, é necessário que professores e alunos se transformem, no cotidiano de suas práticas, em sujeitos do seu ensinar e do seu aprender, do ato do ensino/aprendizagem". Outro fator importante diz respeito à forma como o professor e à escola conduzem o desenvolvimento de suas atividades e/ou ações, em busca dos objetivos de desenvolvimento profissional de sua equipe e, principalmente, de uma formação significativa para seus alunos (MARCELO GARCÍA, 1999).

Assim, esses foram os fenômenos que explicitaram os momentos de passagem de aluno a professor durante os ECS I-II-III, percebidos e apontados pelos acadêmicos estudados. 
Desta forma, a partir da identificação destes momentos, apresentados pelos acadêmicos estudados, podemos compreender que a 'passagem de aluno a professor' perpassa situações variadas, não lineares, singulares e, muitas vezes, desconhecidas, mas que estão intimamente relacionados com as suas experiências de aprendizagem profissional da docência, pois em decorrência dessas é detonado o "processo de passagem de se ver como aluno para o se ver como professor" (PIMENTA, 2008, p. 20). Assim, esses momentos citados pelos acadêmicos estudados estão vinculados à realidade concreta da atividade docente.

\section{As transformações ocasionadas pelos momentos de passagem de aluno a professor na percepção dos acadêmicos estudados}

Os depoimentos mostraram que todos os acadêmicos perceberam transformações ocasionadas pelos momentos de passagem de aluno a professor durante a realização dos ECS I-II-III do curso de Licenciatura em Educação Física do CEFD/UFSM. Desta forma, na constante busca pela resposta dos objetivos e entender o processo que norteia este estudo, nos deparamos com relatos que nos remetem a compreender as transformações ocasionadas pelos momentos debatidos na seção anterior.

Neste sentido, o fenômeno do desenvolvimento da responsabilidade, seriedade e comprometimento de desempenhar um bom trabalho docente foi uma transformação percebida pelos acadêmicos que participaram do estudo. Freire (1996) destaca que ensinar não é transferir conhecimento, mas criar as possibilidades para a sua produção ou a sua construção, e nas condições de verdadeira aprendizagem os educandos vão se transformando em reais sujeitos na construção e reconstrução do saber ensinado, ao lado do educador, igualmente sujeito desse processo. Kunz (1991) contribui com essa reflexão ao observar que o ensino está atrelado ao conhecimento e experiência dos professores. Somente ele decide e determina o que deve acontecer nas aulas de Educação Física. Entretanto, pode-se dizer que a função do professor é a de promover o entendimento dos vários sentidos que a Educação Física possa ter para os alunos, bem como de resolver os conflitos que possam surgir em sua aula para que haja harmonia e ocorra uma aprendizagem significativa. Dessa forma, Pimenta e Lima (2004, p. 61) colocam que "[...] o estágio como campo de conhecimento e eixo central dos cursos de 
formação de professores possibilita que sejam trabalhados aspectos indispensáveis à construção da identidade, dos saberes e das posturas específicas ao exercício profissional".

Esta perspectiva de encarar o estágio, como balizador da formação inicial nas licenciaturas, motivou os acadêmicos estudados, a compreender o fenômeno de seu papel na conscientização que o seu ato educativo pode e deve contribuir na formação dos estudantes. Em relação a essa transformação, Marques; Ilha e Krug (2009) enfatizam sobre a importância de o professor conhecer seus alunos para construir uma boa base de confiança, se interessando em saber dos seus anseios, para poder exigir mais ou menos deles. Segundo os autores é importante procurar sempre ter uma boa relação com os alunos, rompendo com a ideia tradicional de que aluno só aprende e que o professor é um mero instrumento de transmissão de conhecimentos. Além disso, é fundamental voltarmos os olhares à formação inicial de professores de Educação Física, em especial, à disciplina de ECS e o planejamento das aulas ministradas pelos acadêmicos que irão contribuir na formação dos alunos. Concordamos com Miranda (2008, p. 18) quando observa que o acadêmico em situação de estágio está com sua "identidade em formação respaldada pelos saberes instituídos e pelo confronto das representações acerca desses saberes e das demandas educacionais e sociais".

O envolvimento com as atividades do ECS, segundo os acadêmicos, como um fenômeno, promove a articulação entre a teoria estudada e a realidade prática da escola. Através dessa transformação é possível perceber que esses passaram a ter uma compreensão mais ampla da Educação Física na escola. Visão essa que contribui para a construção de uma identidade da disciplina mais adequada ao processo de educação escolar que vem se buscando ao longo dos anos.

Nessa perspectiva, o professor, cuja 'atividade predominante' é ensinar, visa o desenvolvimento dos estudantes com os quais interage e que pode ser impulsionado por uma organização do ensino capaz de promover ações voltadas à aprendizagem de conceitos por parte dos próprios estudantes (SERRÃO, 2006, p. 126). Também durante o estágio, diversas são as inquietudes que ocorrem na prática pedagógica do acadêmico, pois é nesse momento que acontece o confronto direto entre a teoria e a prática. Krug (2001) ainda observa que é importante o professor 'refletir na' e 'sobre a sua ação', 
porque dessa forma estará supervalorizando o 'saber', o 'fazer' e o 'por que fazer', que são fontes do processo de produção de conhecimento.

Outro fenômeno que se materializa nos depoimentos dos acadêmicos é o enfrentamento das dificuldades da docência. Sobre essa transformação ocasionada pelos momentos de passagem de aluno a professor, Flores et al. (2010) observa que aprender a lidar com problemas e procurar soluções é uma das aprendizagens docentes dos acadêmicos em situação de estágio. Sabemos que diversas são as dificuldades encontradas no contexto escolar, mas essas servem de experiência e aprendizado para o desenrolar da vida profissional do professor. Além disso, Krug (2001) contribui, destacando que a capacidade de enfrentar as constantes inovações no exercício da docência é facilitada quando há associações, grupos, que buscam orientações comuns visando o aperfeiçoamento profissional.

Ainda outro fenômeno que é facilmente descortinado nos depoimentos dos acadêmicos como uma transformação é o tratamento de igualdade nas relações estabelecidas com os pares na escola. Compreendemos que a realidade do dia-a-dia da escola é uma instância privilegiada para a formação dos acadêmicos e sua interação com o ambiente escolar, pois os futuros professores têm de ter conhecimento sobre os alunos, seus pares e a escola como um todo. No entanto, o fato de os professores de Educação Física, muitas vezes, não participarem efetivamente das atividades da escola, reuniões, conselhos de classe, e em outros segmentos, tem um significado valorativo, uma vez que, no âmbito geral do ensino, as matérias mais valorizadas são o Português e a Matemática, deixando as demais disciplinas em segundo plano, como no caso da Educação Física. A respeito disso, Nunes (2001) coloca que o professor de Educação Física deve participar das atividades que envolvem o trabalho de educação escolar, principalmente nas reuniões pedagógicas, pois é nessas reuniões que são traçados planejamentos que darão o direcionamento que os professores devem seguir. Além disso, é nesses momentos que acontecem as trocas de experiências e aprendizados necessários e que beneficiam a boa relação com os colegas, supervisão, direção, enfim, a escola como um todo.

O debate acirra a compreensão sobre o cuidado de ter sempre um propósito, um objetivo a alcançar, como mais um fenômeno de transformação ocasionado pelos 
momentos de passagem de aluno a professor. Para Marques; Ilha e Krug (2009) um dos aspectos de grande importância na prática pedagógica dos professores refere-se à preocupação com o planejamento. Tendo em vista que ele orienta toda docência do professor para que esse desenvolva um trabalho com propósito, coerente e com seguimento ao se configurar em uma estratégia de acompanhamento diário dos objetivos que vem atingindo, ou não, no que tange à aprendizagem dos seus alunos. Em meio a essa realidade, existe a preocupação com a aprendizagem e desenvolvimento dos alunos, pois 'ser professor' não é simplesmente dar aula, expor ideias, mas sim encontrar uma forma para que os alunos aprendam na medida em que interajam e exponham suas ideias na construção do seu conhecimento.

É importante salientar que o papel do acadêmico/professor na organização do ensino é insubstituível, porque é ele o responsável por criar situações em que se apresentam problemas de aprendizagem que considerem o nível de desenvolvimento real dos estudantes, instigando e promovendo a atuação desses em sua zona de desenvolvimento proximal ou potencial (SERRÃO, 2006). Dessa forma, a prática docente do professor passa a ser construída e reconstruída juntamente com as necessidades que se fazem presentes nos processos de ensino-aprendizagem. Como salienta Zabala (1998), educar quer dizer formar cidadãos e cidadãs, que não estão parcelados em compartimentos estanques, em capacidades isoladas.

O resultado da compreensão sobre o ser professor pelos acadêmicos estudados se estabelece na incorporação do papel de professor como mais um fenômeno. Assim, essa transformação ocasionada pelos momentos de passagem de aluno a professor pode ser fundamentada por Perlozo (2007), que destaca que o estágio por si só não garante uma preparação completa para a docência do futuro professor, mas dá oportunidades para que esse "futuro educador tenha noções básicas do que é ser professor nos dias atuais" (p. 2), conhecendo a realidade em que estão inseridos os alunos. Essa possibilidade de observar e refletir sobre a sua prática permitirá, segundo a mesma autora, que "o aluno/estagiário reafirme sua escolha pela profissão e resolva assumir-se como profissional politizado desde o início de sua carreira" (p. 2). Além disso, segundo Zabala (1998), torna-se importante salientar que o professor é o responsável por promover a aprendizagem dos seus alunos e nesse sentido, deverá ter o conhecimento dos fatores 
que poderão vir a ser benéficos e maléficos para que ela se concretize, visando a um melhor aproveitamento e aprendizagem duradouros.

O estudante no estágio passa da situação de aluno para a posição de professor devendo, portanto, assumir uma nova postura no processo de ensino. Além disso, é importante salientar o que afirma Pérez Gómez (1992), que o êxito do professor depende da sua capacidade para manejar a complexidade do ato pedagógico e resolver problemas práticos, através da integração inteligente e criativa do conhecimento e da técnica. Tardif (2002) contribui ao afirmar que a competência do professor está intimamente ligada com o seu saber de conteúdo, apresentando desse modo o processo de complexificação da prática docente. Os professores, após reflexões sobre o que é o conhecimento e como ele pode ser aprendido e apreendido, passam a pensar na sua constituição, nos saberes que, de algum modo, permitem uma prática docente mais objetiva e promotora da aprendizagem e desenvolvimento de seus alunos.

Portanto, a responsabilidade intelectual aparece como um fenômeno de transformação ocasionado pelo momento de passagem de aluno a professor. Para Marcelo Garcia (1999), o ECS representa a oportunidade privilegiada para aprender a ensinar na medida em que se integram às diferentes dimensões que envolvem a atuação docente. Ou seja, o conhecimento psicopedagógico, o conhecimento do conteúdo e o conhecimento didático do conteúdo. Dessa forma, o estágio pedagógico constitui-se num espaço privilegiado de interface da formação teórica com a vivência profissional. Essa interface teórico-prática compõe-se de uma interação constante entre o saber e o fazer, entre os conhecimentos acadêmico-disciplinares e o enfrentamento dos problemas decorrentes da vivência de situações próprias do cotidiano escolar (MIRANDA, 2008).

Assim, essas foram as transformações ocasionadas pelos momentos de passagem de aluno a professor durante os ECS I-II-III, percebidos e apontados pelos acadêmicos estudados.

Desta forma, a partir da identificação destas transformações, podemos compreender que elas estão intimamente relacionadas à experiência adquirida como professor durante os ECS I-II-III. Segundo Cavalheiro et al. (2009), é comum ouvir dos estagiários que o ECS é importante para que os acadêmicos adquiram experiência como professor. Ainda podemos inferir que essa experiência adquirida está relacionada com os 
saberes experienciais desenvolvidos durante os estágios. De acordo com Pimenta (2008), a constituição do 'ser professor' ou do processo de passar a 'se ver como professor' está intimamente relacionado ao desenvolvimento da experiência na sua prática diária.

\section{Considerações transitórias: uma possível interpretação sobre a investigação}

A partir do processo que envolveu a análise das informações, organização da essência dos fenômenos e debate com o referencial teórico, buscamos neste momento possíveis respostas ao objetivo do estudo: analisar como acontece a passagem de aluno a professor durante a realização dos ECS I-II-III, na percepção dos acadêmicos da Licenciatura em Educação Física do CEFD/UFSM.

Desta forma, identificamos alguns (seis) momentos correspondentes a essa passagem na percepção dos acadêmicos participantes do estudo: a inserção na escola; a regência da disciplina de Educação Física; a relação com os estudantes na escola; o ser chamado de professor pelos estudantes; as tomadas de decisões frente aos acontecimentos das aulas; e, a constatação de mudanças relativas aos conhecimentos dos estudantes.

Também constatamos que foi possível identificar algumas (oito) transformações ocasionadas por essa passagem na percepção dos acadêmicos estudados: a responsabilidade, seriedade e comprometimento de desempenhar um bom trabalho docente; a conscientização que o seu ato educativo pode e deve contribuir na formação dos estudantes; a articulação entre a teoria estudada e a realidade da prática da escola; o enfrentamento das dificuldades da docência; o tratamento de igualdade nas relações estabelecidas com os pares na escola; o cuidado de ter sempre um propósito, um objetivo a alcançar; a incorporação do papel de professor; e, a responsabilidade intelectual.

A partir destas constatações podemos inferir que o ECS é um componente curricular importante na constituição do 'ser professor' de Educação Física durante a formação inicial. Conforme Ivo e Krug (2008), o ECS é o momento em que o acadêmico confronta-se com a escola, e com a futura profissão, 'ser professor'. Nesse sentido, Guarnieri (1996) advoga pela ideia de que é no exercício da profissão que se consolida o 
processo de 'tornar-se professor', ou seja, o aprendizado da profissão a partir de seu exercício possibilita configurar como é construída a função docente.

Entretanto, um dos grandes problemas de se estudar a 'passagem de aluno a professor', comentado por Leone e Leite (2011), é que alguns autores defendem que, no período da formação inicial, por ocasião das atividades de estágio e prática de ensino, a relação que os alunos (acadêmicos) dos cursos de Licenciatura mantêm com o campo profissional da docência é de caráter exógeno, visto que eles ainda não se constituem efetivamente como profissionais. Assim, segundo Lima et al. (2007), é somente no período de sua inserção profissional na docência que os novos professores enfrentarão, pela primeira vez, a realidade cotidiana de uma atividade de trabalho na qualidade de professores plenamente qualificados.

Neste sentido, perante as afirmações supracitadas, consideramos pertinente, para defender a ideia deste estudo, citar Silva e Krug (2010) que colocam que ser professor é um processo que se desenvolve no tempo. Começa antes de iniciar o processo de formação e prolonga-se ao longo da vida, atravessando múltiplos contextos, vivendo vários dilemas, construindo conhecimentos em vários domínios. É um processo que atravessa toda a vida dos sujeitos. Já Krug; Ivo e Krug (2009) afirmam que os processos de aprender a ser professor passam pelos nossos desejos, sentidos e emoções voltados para um determinado foco, podendo possibilitar e estabelecer relações com os conhecimentos já internalizados. Dessa forma, segundo Pimenta (2008), o desafio dos cursos de formação inicial é o de colaborar no processo de passagem dos acadêmicos do se ver como aluno ao se ver como professor, ou seja, de construir a sua identidade de professor, na qual os saberes das experiências são importantes, mas somente isso não basta, é insuficiente. A docência representa um desafio e exige conhecimentos, competências e preparação específica para o seu exercício. Assim, ao considerarmos todos esses pressupostos é que destacamos a importância da realização desta investigação. 


\section{Referências}

BARDIN, Laurence. Tradução de Luis Antero Neto e Augusto Pinheiro. Análise de conteúdo. Lisboa: Edições 70, 1977.

BERNARDI, Ana Paula et al. Formação inicial: a disciplina de prática de ensino como meio de experimentar a educação física escolar. In: KRUG, Hugo Norberto; KRÜGER, Leonardo Germano; CRISTINO, Ana Paula da Rosa (Orgs.). Os professores de educação física em formação. Santa Maria: Universidade Federal de Santa Maria, Centro de Educação, Programa de Pós-Graduação em Educação, 2008. p.14-21.

BRASIL. Conselho Nacional de Educação. Conselho Pleno. Resolução CNE/CP Nº 01 , de 18 de fevereiro de 2002: institui diretrizes curriculares nacionais para a formação de professores da educação básica, em nível superior, curso de licenciatura, de graduação plena. Brasília, DF, 2002a. Disponível em:

<http://portal.mec.gov.br/cne/arquivos/pdf/rcp01_02.pdf>. Acesso em 03 de dezembro de 2014.

BRASIL. Conselho Nacional de Educação. Conselho Nacional de Educação. Conselho Pleno. Resolução CNE/CP Nº2, de 19 de fevereiro de 2002: institui a duração e a carga horária dos cursos de licenciatura, de graduação plena, de formação de professores da educação básica em nível superior. Brasília, DF, 2002b. Disponível em:

<http://portal.mec.gov.br/cne/arquivos/pdf/CP022002.pdf>. Acesso em 03 de dezembro de 2014 .

CAVALHEIRO, Lais et al. Formação inicial: a opinião dos acadêmicos sobre alguns elementos da prática pedagógica vivenciados na disciplina de estágio curricular supervisionado. Boletim Brasileiro de Educação Física, Brasília, n.73, p.1-8, fev./mar., 2009. Disponível em: <http://www.boletimef.org/?canal=12\&file=2179> . Acesso em: 10 mar. 2009.

UNIVERSIDADE FEDERAL DE SANTA MARIA. CENTRO DE EDUCAÇÃO FÍSICA E DESPORTOS/ Projeto político pedagógico do curso de licenciatura em educação física. Santa Maria: UFSM/CEFD, 2005.

CHICATI, Karen Cristina. Motivação nas aulas de educação física no ensino médio. Revista da Educação Física/UEM. Maringá, v.11, n.1, p.97-105, 2000.

CUNHA, Maria Izabel. A relação professor-aluno. In: VEIGA, Ilma Passos Alencastro (Coord.). Repensando a didática. 11 ed. Campinas: Papirus, 1996.

FAZENDA, Ivani (Org.). Metodologia da pesquisa educacional. São Paulo: Cortez, 1989.

FLORES, Patric Paludett et al. A importância do estágio curricular supervisionado para a formação profissional em educação física: uma visão discente. Boletim Brasileiro de Educação Física, Brasília, v.10, n.1, p.1-9, jan./fev., 2010. Disponível em: <http://www.boletimef.org/bibliotece/2667/Importancia-do-estagio-na-formacao-em-E...>. Acesso em: 18 jan. 2010.

FREIRE, Paulo. Pedagogia da autonomia: saberes necessários à prática educativa. 30. ed. São Paulo: Paz e Terra, 1996. 
GUARNIERI, Maria Regina. Tornar-se professor: o início da carreira docente e a consolidação na profissão, 1996. 149 f. Tese (Doutorado em Educação) - Universidade Federal de São Carlos, São Carlos, 1996.

GODOY, Arilda Schmidt. Pesquisa qualitativa: tipos fundamentais. Revista de Administração de Empresas, São Paulo, v.35, n.3, p.20-29, mai./jun.,1995.

GOODE, Willian J.; HATT, Paul K. Métodos em pesquisa social. São Paulo: Cia. Editora Nacional, 1968.

ILHA, Franciele Roos da Silva et al. O encadeamento dos estágios curriculares supervisionados no curso de licenciatura em educação física do CEFD/UFSM. Boletim Brasileiro de Educação Física, Brasília, n.73, p.1-9, fev./mar., 2009. Disponível em: <http://www.boletimef.org/?canal=12\&file=2167>. Acesso em: 10 mar. 2009.

ILHA, Franciele Roos da Silva; KRUG, Rodrigo de Rosso; KRUG, Hugo Norberto. A experiência docente na prática de ensino/estágio curricular supervisionado em educação física dos acadêmicos do CEFD/UFSM (Currículo 1990). Revista Pedagógica, Chapecó, a.11, n.22, p.85-108, jan./jun., 2009. Disponível em:

<http://www.apps.unochapeco.edu.br/revistas/index.php/pedagogia/issue/current>. Acesso em: 21 set. 2009.

ISAIA, Silvia Maria de Aguiar. Trajetória pessoal; trajetória profissional; aprendizagem docente. In: MOROSINE, Marilia (Org.). Enciclopédia de pedagogia universitária: glossário. Brasília: INPE, 2006.

IVO, Andressa Aita; KRUG, Hugo Norberto. O estágio curricular supervisionado e a formação do futuro professor de educação física. Revista Digital Lecturas: Educación Física y Deportes, Buenos Aires, a.13, n.127, p. 1-18, diciembre, 2008. Disponível em: http://www.efdeportes.com/efp127/a-formação-do-futuro-professor-de-educação-fisica... . Acesso em: 5 dez. 2008.

KRUG, Hugo Norberto. Ensino reflexivo: uma alternativa para a prática de ensino e para a formação profissional em educação física. In: KRUG, Hugo Norberto. (Org.). Formação de professores reflexivos: ensaios e experiências. Santa Maria: O Autor, 2001. p.33-42.

KRUG, Rodrigo de Rosso; KRUG, Hugo Norberto. Os estágios curriculares supervisionados I-II-III na licenciatura do CEFD/UFSM: a confirmação ou não do ser professor de Educação Física... na escola, 2012. Relatório de Pesquisa (Artigo Não Divulgado) - Universidade Federal de Santa Maria, Santa Maria, 2012.

KRUG, Rodrigo de Rosso; IVO, Andressa Aita; KRUG, Hugo Norberto. As lembranças significativas do tempo da educação física escolar na educação básica pelos licenciandos do CEFD/UFSM: colaborando com o "aprender a ser professor". Boletim Brasileiro de Educação Física, Brasília, n.73, p.1-9, fev./mar., 2009. Disponível em: http://www.boletimef.org/?canal=12\&file=2174. Acesso em: 10 mar. 2009.

KRÜGER, Leonardo Germano; CONCEIÇÃO, Victor Julierme Santos da; KRUG, Hugo Norberto. Aprendendo a ser professor na prática pedagógica educativa no estágio curricular supervisionado: reflexões da educação física escolar. In: KRUG, Hugo Norberto. (Org.). Saberes e fazeres na educação física. Santa Maria: [s.n.], 2007. p.41-45. 
KUNZ, Elenor. Educação física: ensino e mudança. ljuí: Editora Unijuí, 1991.

LEONE, Naira Mendonça; LEITE, Yoschie Ussami Ferrari. O início da carreira docente: implicações à formação inicial de professores. Revista Eletrônica Pesquiseduca, Santos, v.03, n.06, p.236-259, jul./dez., 2011.

LIMA, Emília Feitas de et al. Sobrevivendo ao início da carreira docente e permanecendo nela: como? porque? o que dizem alguns estudos. Revista Educação e Linguagem, São Paulo, a.10, n.15, p.138-160, jan./jun., 2007.

LÜDKE, Menga; ANDRÉ, Marli E.D.A. Pesquisa em educação: abordagens qualitativas. São Paulo: EPU, 1986.

MARCELO GARCIA, Carlos. Formação de professores: para uma mudança educativa. Porto: Porto Editora, 1999.

MARQUES, Marta Nascimento; ILHA, Franciele Roos da Silva; KRUG, Hugo Norberto. O planejamento e o desempenho dos acadêmicos de educação física na sua prática de ensino: um estudo de caso no Centro de Educação Física e Desportos da Universidade Federal de Santa Maria. In: CONGRESSO DE EDUCAÇÃO, ARTE E CULTURA, 2., 2009, Santa Maria. Confluências e diálogos no campo das artes. Anais... Santa Maria: UFSM, 2009.

MARQUES, Mário Osório. A questão dos conteúdos de ensino. Revista Contexto \& Educação, ljuí, a.4, n.15, 1989.

MIRANDA, Maria Irene. Ensino e pesquisa: o estágio como espaço de articulação. In: SILVA, Lazara Cristina; MIRANDA, Maria Irene (Orgs.). Estágio supervisionado e prática de ensino: desafios e possibilidades. Araraquara: Junqueira\&Marin/ Belo Horizonte: FAPEMIG, 2008. p.15-36.

MOLINA NETO, Vicente. Etnografia: uma opção metodológica para alguns problemas e investigação no âmbito da Educação Física. In: MOLINA NETO, Vicente.; TRIVIÑOS, Augusto Nibaldo Silva (Orgs.). A pesquisa qualitativa em educação física: alternativas metodológicas. Porto Alegre: Sulina, 2004.

NUNES, Fábio Santana. Educação física frente ao processo de terceirização, 2001. Trabalho Monográfico de Conclusão de Curso (Licenciatura em Educação Física) Universidade Estadual de Feira de Santana, Feira de Santana, 2001.

PÉREZ GÓMEZ, Angel I. O pensamento prático do professor: a formação do professor como profissional reflexivo. In: NÓVOA, Antônio (Coord.). Os professores e sua formação. Lisboa: Publicações Dom Quixote, 1992. p.93-114.

PERLOZO, Raquel C.B. Prática de ensino e estágio supervisionado enquanto mediação entre ensino, pesquisa e extensão. Revista Eletrônica de Pedagogia, São Paulo, a.V, n.10, jul., 2007.

PIMENTA, Selma Garrido. Formação de professores: identidade e saberes da docência. In: PIMENTA, Selma Garrido. (Org.). Saberes pedagógicos e atividade docente. 6. ed. São Paulo: Cortez, 2008. p.15-34.

PIMENTA, Selma Garrido; LIMA, Maria do Socorro Lucena. Estágio e docência. São Paulo: Cortez, 2004. 
SANTOS JÚNIOR, Sidnei Lopes dos; KRUG, Hugo Norberto. Extensão universitária: contribuições à formação inicial em educação física da UFSM. In: KRUG, Hugo Norberto (Org.). Os professores de educação física e sua formação. Santa Maria: Universidade Federal de Santa Maria, 2008. p.49-55.

SERRÃO, Maria Isabel Batista. Aprender a ensinar: a aprendizagem do ensino no curso de pedagogia sob o enfoque histórico-cultural. São Paulo: Cortez, 2006.

SILVA, Alexandra Rosa. As trajetórias formativas de acadêmicos de educação física do curso de licenciatura da UFSM: contribuições na constituição do ser professor, 2010. Dissertação (Mestrado em Educação) - Universidade Federal de Santa Maria, Santa Maria, 2010.

SILVA, Alexandra Rosa; KRUG, Hugo Norberto. Aprendendo a ser professor: a dinâmica da trajetória que tece as concepções da formação profissional na Educação Física. Revista Digital Lecturas: Educación Física y Deportes, Buenos Aires, a.14, n.140, p.1-6, enero, 2010. Disponível em: http://www.efdeportes.com/ef140/aprendendo-a-ser-professor-deeducacao-fisica-no-estagio-urricular-supervisionado.htm . Acesso em: 25 jan. 2010.

TARDIF, Maurice. Saberes docentes e formação profissional. Petrópolis: Vozes, 2002.

TARDIF, Maurice; LESSARD, Claude; LAHAYE, Louise. Os professores face ao saber: esboço de uma problemática do saber docente. Revista Teoria \& Educação, n.4, p.215-233, 1991.

TRIVIÑOS, Augusto Nibaldo Silva. Introdução à pesquisa em ciências sociais: pesquisa qualitativa em educação. São Paulo: Atlas, 1987.

VEIGA, Ilma Passos Alencastro. A profissionalização docente: uma construção histórica e ética. In: VEIGA, Ilma Passos Alencastro; ARAÚJO, José Carlos Souza; KAPUZINIAK, Célia (Orgs.). Docência: uma construção ética-profissional. Campinas: Papirus, 2005.

ZABALA, Antonio. A prática educativa: como ensinar. Porto Alegre: ArtMed, 1998.

Recebido em: 27/05/2013 Aprovado em: 26/02/2014

Universidade do Estado de Santa Catarina - UDESC Programa de Pós-Graduação em Educação - PPGE Revista Linhas Volume 16 - Número 30 - Ano 2015 revistalinhas@gmail.com 